\title{
Qualidade de resistência de peles de tilápia e salmão submetidas ao processo de curtimento com tanino vegetal
}

\author{
Strength quality of tilapia and salmon skins submitted to tanning process with vegetable tannin \\ Calidad de resistencia de las pieles de tilapia y salmón sometidas a proceso de curtido con tanino
}

vegetal

Recebido: 16/06/2021 | Revisado: 23/06/2021 | Aceito: 05/07/2021 | Publicado: 15/07/2021

\author{
Marcos Antonio Matiucci \\ ORCID: https://orcid.org/0000-0003-2053-2672 \\ Universidade Estadual de Maringá, Brasil \\ E-mail: m.matiucci@hotmail.com \\ Andresa Carla Feihrmann \\ ORCID: https://orcid.org/0000-0003-2389-0467 \\ Universidade Estadual de Maringá, Brasil \\ E-mail: andresafeihrmann@gmail.com \\ Gislaine Gonçalves Oliveira \\ ORCID: https://orcid.org/0000-0002-7819-3493 \\ Universidade Estadual de Maringá, Brasil \\ E-mail: gislaine_oliveira14@hotmail.com \\ Stefane Santos Corrêa \\ ORCID: https://orcid.org/0000-0001-6519-2400 \\ Universidade Estadual de Maringá, Brasil \\ E-mail: stefane.pescap@gmail.com \\ Elenice Souza dos Reis Goes \\ ORCID: https://orcid.org/0000-0003-2437-4800 \\ Universidade Federal da Grande Dourados, Brasil \\ E-mail: elenicegoes@ufgd.edu.br \\ Maria Luiza Rodrigues de Souza \\ ORCID: https://orcid.org/0000-0001-5643-0841 \\ Universidade Estadual de Maringá, Brasil \\ E-mail:mlrsouza@uem.br
}

\begin{abstract}
Resumo
Com o aumento da produção aquícola, cresce também a quantidade de resíduos gerados, tal como a pele dos peixes. O objetivo deste trabalho foi realizar análises físico-mecânicas de couros de tilápia do Nilo (Oreochromis niloticus) e Salmão (Salmo salar) submetidos ao curtimento com tanino vegetal. Foram retirados corpos de provas no sentido longitudinal, para a determinação da resistência à tração, alongamento e rasgamento progressivo dos couros. Os couros de salmão apresentaram parâmetros de resistência semelhantes ou superiores aos couros de tilápia. O couro de salmão apresentou $96 \%$ de alongamento, a uma força máxima de $161,75 \mathrm{~N}$, enquanto o couro de tilápia $114,75 \%$ e $127,00 \mathrm{~N}$, respectivamente para estes mesmos parâmetros. A força aplicada foi de 53,62N para gerar um rasgo de $53,60 \mathrm{~N} / \mathrm{mm}$, para os couros de salmão, já os couros de tilápia apresentou um rasgo de 40,56N/mm submetido a uma força de $36,75 \mathrm{~N}$. Os couros de salmão apresentaram qualidade de resistência semelhante ou superiores aos couros de tilápia dependendo do parâmetro avaliado.
\end{abstract}

Palavras-chave: Couro; Metal-free; Oreochromis niloticus; Salmo salar.

\begin{abstract}
With the increase in aquaculture production, the amount of waste generated, as well as the skin of fish, also grows. The objective of this work was to carry out physical-mechanical analyzes of Nile tilapia (Oreochromis niloticus) and Salmon (Salmo salar) leathers submitted to tanning with vegetable tannins. Longitudinal specimens were removed to determine the tensile strength, elongation and progressive tearing of the leathers. Salmon leathers showed resistance parameters similar or superior to tilapia leathers. Salmon leather showed $96 \%$ elongation, at a maximum strength of $161.75 \mathrm{~N}$, while tilapia leather $114.75 \%$ and $127.00 \mathrm{~N}$, respectively for these same parameters. The applied force was $53.62 \mathrm{~N}$ to generate a tear of $53.60 \mathrm{~N} / \mathrm{mm}$, for salmon leathers, whereas tilapia leathers showed a tear of $40.56 \mathrm{~N} / \mathrm{mm}$ submitted to a force of $36.75 \mathrm{~N}$. Salmon leathers presented resistance quality similar or superior to tilapia leathers depending on the evaluated parameter.
\end{abstract}

Keywords: Leather; Metal-free; Oreochromis niloticus; Salmo salar. 


\begin{abstract}
Resumen
Con el aumento de la producción acuícola, también crece la cantidad de desechos generados, así como la piel de los peces. El objetivo de este trabajo fue realizar análisis físico-mecánicos de cueros de tilapia del Nilo (Oreochromis niloticus) y salmón (Salmo salar) sometidos a curtido con taninos vegetales. Se retiraron probetas longitudinales para determinar la resistencia a la tracción, elongación y el desgarro progresivo de las pieles. Los cueros de color salmón mostraron parámetros de resistencia similares o superiores a los cueros de tilapia. El cuero de salmón mostró un alargamiento del $96 \%$, con una resistencia máxima de $161,75 \mathrm{~N}$, mientras que el cuero de tilapia mostró un $114,75 \%$ y $127,00 \mathrm{~N}$, respectivamente para estos mismos parámetros. La fuerza aplicada fue $53.62 \mathrm{~N}$ para generar un desgarro de $53.60 \mathrm{~N} / \mathrm{mm}$, para cueros de salmón, mientras que los cueros de tilapia mostraron un desgarro de $40.56 \mathrm{~N} / \mathrm{mm}$ sometidos a una fuerza de $36.75 \mathrm{~N}$. Los cueros de salmón presentaron una calidad de resistencia similar o superior a los cueros de tilapia según el parámetro evaluado.
\end{abstract}

Palabras clave: Cuero; Libre de metales; Oreochromis niloticus; Salmo salar.

\title{
1. Introdução
}

$\mathrm{O}$ aumento significativo da aquicultura brasileira e a mudança de perfil do consumidor estão despertando o interesse em relação à industrialização de pescado, pois há um crescente aumento por alimentos que contenham qualidades nutricionais e praticidade. Algumas espécies de peixes têm apresentando interesse no cultivo, com destaque por ser economicamente explorável. Mas, dentre as espécies cultivadas, a tilápia do Nilo (Oreochromis niloticus) é a espécie mais produzida no Brasil, representando 60\% de toda a produção (IBGE, 2019). Tal fato se deve a sua adaptabilidade ao clima, rusticidade, aceitação de diferentes sistemas de produção, grande demanda do produto, bons índices zootécnicos, além de versatilidade na culinária (Araujo \& Reynol, 2017), assim como, suas características tecnológicas da carne, tais como a coloração branca de textura firme e não possui espinhas que forma um Y (Simões et al., 2007). Existem algumas formas de comercialização disponíveis no país, porém a sua principal forma de comercialização é em filés sem pele e congelados (Simões et al., 2007). Todavia, algumas espécies de peixes marinhos têm uma grande importância, principalmente, na culinária japonesa. Dentre essas espécies, o salmão da família Salmonidae, apreciado pela carne rosada e saborosa, devido ao pigmento da dieta à base do camarão Krill. Essa característica de coloração é importantíssima para essa espécie. A maioria dos salmões consumidos mundialmente são de cultivo, em fazendas subaquáticas e a cor de sua pele vai do cinza ao bege claro e para que a carne apresente a mesma tonalidade da carne do salmão tradicional (da natureza), esses peixes recebem uma ração com aditivos sintéticos, para a obtenção da cor desejada da carne.

Com aumento da produção aquícola, principalmente pelos peixes industriais (voltados para o processo de filetagem) e elevada quantidade de resíduos gerada no abate, podendo levar ao impacto ambiental. De acordo com Kubitza (2006) a tilápia do Nilo, gera de 60 a 72\% de resíduos, sendo considerada uma elevada quantidade e muitas vezes não tendo um destino ecologicamente adequado. Já o salmão, no processamento gera cerca de 40 a $60 \%$ de resíduos, inferior ao de tilápia, mas que normalmente é destinado à produção de farinhas e óleos (Dragnes et al, 2009). Mas, as peles em geral são mantidas nos filés de salmão, para a comercialização, no entanto, para determinados pratos oferecidos pela culinária, há necessidade da extração dessa pele que normalmente é descartada (Franco et al., 2013). De acordo com esses autores a pele de salmão é considerada grande, por pesar entre 80 a $150 \mathrm{~g}$ a unidade e de cada peixe, pode-se aproveitar as duas unidades retiradas dos dois filés gerados no processo de filetagem.

É de suma importância o desenvolvimento de formas de aproveitamento dos resíduos gerados no processo de filetagem, tais como, cabeças, escamas, peles, vísceras, carcaça, e espinhaço, e assim melhorar a eficiência na tentativa de um aproveitamento integral do pescado, proporcionando uma sustentabilidade econômica no setor. Franco (2011) relatou que no processo de filetagem, a pele de peixe, representa em média 7,5\% do seu peso total e, é considerado um subproduto que pode ser beneficiado por um processo de curtimento e transformado a pele em couro, um material imputrescível e resistente. Há fatores que podem estar relacionados com a resistência do couro que vão desde os relacionados ao peixe (espécie, idade, peso, 
comprimento, quanto ao sentido transversal ou longitudinal de retirada do corpo de prova, associada a estrutura histológica da pele), conservação, armazenamento, tipo de processo de curtimento utilizado para transformer as peles em couros, entre outros (Godoy et al., 2010; Franco et al., 2013).

$\mathrm{O}$ processo de curtimento está altamente relacionado com os tipos e concentrações de produtos químicos, tempo e pH em cada etapa do processo (Souza, 2004; Franco, 2011). As enzimas na etapa de purga, a forma de aplicação dos ácidos (no píquel), agentes curtentes, óleos (temperatura da solução) e fixação com a redução do $\mathrm{pH}$ dos couros (pH final no processo) que são importantes para garantir a qualidade de fixação dos agentes curtentes, corantes e óleos adicionados durante o processamento. A ação mecânica em cada etapa do processo também interfere no processo de curtimento (Neu et al., 2015).

No processo de curtimento de couros, têm-se a aplicação de taninos vegetais, sintéticos e minerais. Os taninos são moléculas fenólicas biodegradáveis encontradas e extraídas de cascas de árvores, principalmente da acácia negra, cujas características inibem o processo de putrefação de peles (Hoinacki, 1989). Dessa forma, o curtimento com tanino vegetal é uma alternativa para minimizar os danos causados ao meio ambiente. Sendo os taninos vegetais extraídos de plantas, os sintéticos que são com sais minerais alternativos que permitem a substituição parcial do cromo, utilizados para o processo de curtimento sendo assim, denominados de couros wet-white (Sammarco \& Simoncini, 19940). Dentre os três tipos de agentes curtente, o mais simples e empregado mundialmente é a base de cromo (sais de cromo) devido às características proporcionadas ao couro, tais como maior maciez, flexibilidade, toque e resistência, proporcionando um couro de excelente estabilidade e resistência, considerados couros wet-blue

O processo de curtimento com cromo é simples e mundialmente utilizado. Mas, atualmente a busca é por curtimento sem metais pesado, ou seja, bioleather ou metal- free, pela sua utilização promover grande diferencial nos couros curtidos e com melhor aplicabilidade visto a redução do impacto ambiental. De acordo com Fuck et al. (2011) indústrias coureiras têm buscado ainda mais formas de reduzir a utilização do cromo, em função do cromo se encontrar na forma hexavalente no couro, isso possibilita o surgimento de um empecilho quanto a sua utilização, pela utilização de um metal pesado. Proporcionando uma queda na comercialização e consequentemente perdas para a indústria. Atualmente, a procura por artigos de couros ecológicos tem aumentado, estes são os couros curtidos com taninos vegetais, substituindo a utilização dos sais de cromo, que é o agente curtente mais comum usado no processo de curtimento de peles e couros. No entanto, esse cromo se encontra na forma, principalmente, hexavalente (dicromatos), forma esta altamente tóxica para o homem (Pott \& Pott, 1994; Jardim et al., 2004).

Um grande marco na sustentabilidade ambiental dentro do processo de curtimento de couros são técnicas sem aplicação de metais, ou seja "metal-free". chrome-free, metal-free, wet-white e bioleather são técnicas distintas. Chrome-free é ausencia total de cromo, entretanto não significa que há a ausência de outros metais, ou seja, chrome-free não se enquadra no metal-free, onde este é uma técnica com total ausência de metais, já o curtimento wet-white é um termo que emprega o curtimento de cores claras, contudo, não necessariamente metal-free ou chrome-free, por fim tem-se o bioleather, cujo termo emgloba couros metal-free, porém com restrições quanto ao uso de produtos, como nonifezol azo-corantes, formaldeído entre outros (Fasolo, 2011).

Todavia, qualquer um dos diferentes agentes curtentes é muito importante no processo de curtimento, pois é ele que garante a transformação da matéria prima putrescível em imputrescível. Mas, para isso a pele deve ser preparada de forma que as fibras colágenas possam receber adequadamente esses agentes curtentes, através de limpeza da estrutura dérmica, promovido pela abertura do material fibroso, associado a remoção das gorduras naturais das peles e consequentemente a acidifição das fibras colágenas para recebimento do curtente. Sendo assim, com a aplicação do agente curtente a pele se torna um produto imputrescível e com qualidades físico-mecânicas, como maciez, elasticidade, flexibilidade e resistência à tração, que permitem sua aplicação na indústria de confecção de vestuário, calçados ou artefatos em geral (Souza, 2004). 
A utilização de novas tecnologias para agregar valor ao pescado poderá contribuir para o melhor aproveitamento das peles. Dessa forma, o curtimento e recurtimento com tanino vegetal é uma alternativa para minimizar os danos causados ao meio ambiente e a determinação do percentual a ser utilizado na etapa do curtimento. No entanto, um fator importante para utilização dos couros é a sua qualidade de resistência, pois de acordo com Prado et al. (2014) estas variam com a espécie, região e sentido do corte, bem como a técnica de curtimento utilizado. Esta também proporcionará produtos mais elásticos, macios, espessos, acartonados, ou seja, com diferentes características, conforme o desejado para a aplicação na confecção. Para tanto, necessita-se avaliar a resistência desses couros das diferentes espécies de peixes e técnicas empregadas de curtimento para utilizá-las na confecção.

Com o desenvolvimento de pesquisas com curtimento de peles de peixes tanto de água doce como marinha, no que diz respeito a métodos ou técnicas de processamento, com aplicação de agente curtente vegetal, possibilitará um curtimento mais adequadamente ecológica, com menores danos ao ambiente. Quanto menor o impacto ao meio ambiente e melhor qualidade de resistência conferida ao produto, maior será sua aceitação no mercado da confecção em geral.

Sendo assim, o uso de tanino vegetal, se enquadra como uma alternativa tecnológica para o aproveitamento das peles de diferentes espécies de peixes. Para tanto, o objetivo do presente trabalho foi realizar um estudo qualitativo, de acordo com Pereira et al. (2018) e analisar as características mecânicas de couros de tilápia do Nilo (Oreochromis niloticus) e Salmão (Salmo salar) submetidas a técnicas de curtimento com tanino vegetal.

\section{Metodologia}

\subsection{Curtimento das peles}

Para a realização do experimento foram utilizados $6 \mathrm{~kg}$ de peles congeladas de tilápia (Oreochromis niloticus) da Empresa Smart fish (Rolândia-PR) e 6 kg de peles de salmão (Salmo salar) provenientes da Empresa Tomita \& Tomita Ltda (Maringá, PR). O processo de curtimento foi realizado no laboratório de peles e couros da localizado na Fazenda Experimental de Iguatemi, pertencente a Universidade Estadual de Maringá- UEM (PR).

As peles Tilápia do Nilo e de Salmão foram descongeladas, lavadas e pesadas para iniciar o processo de curtimento. As peles foram colocadas na solução de remolho, apenas água e tensoativo $(0,5 \%)$ para ir removendo gordura e auxiliar no processo de descarne das peles de salmão. Apenas as peles de salmão foram descarnadas, pois a retirada da pele dos filés foi manual, enquanto da tilápia foi com auxílio de máquinas especiais para remoção da pele (marca Brusinox). Nestas a quantidade de carne presente na hipoderme era reduzida, não necessitando realizar o descarne. Apenas os produtos químicos são suficientes para remoção dessa pequena quantidade de carne da pele de tilápia. Já para as peles de salmão, o descarne é de extrema importância, em função da espessura de carne que permaneceu na pele após a retirada do filé.

$\mathrm{O}$ caleiro foi a etapa seguinte, realizada de forma estática. Nesta foi adicionado $0,2 \%$ de formol diluído em água com as peles por 10 minutos, depois foram adicionados os demais reagentes ( $2 \%$ de cal, $2 \%$ de soda barrilha, $1 \%$ de tensoativo) por 12 horas. Decorrido esse período a solução foi removida e preparada uma nova solução de caleiro (3\% de cal, 3\% de soda barrilha, $1 \%$ de tensoativo) dentro do fulão, onde permaneceu em rotação por 60 minutos. Após esse período as peles intumescidas foram submetidas a três lavagens e colocadas numa nova solução, a da etapa de desencalagem ( $2 \%$ tensoativo, $2 \%$ de sulfato de amônia), por 60 minutos. Para a purga, utilizou-se 0,3\% de Koropon MK e 1\% de tensoativo (20 minutos) decorrido este período adicionou-se mais $0,2 \%$ de Koropon MK e $1 \%$ de tensoativo, por mais 20 minutos e esgotado a solução. A segunda desencalagem ( $4 \%$ de kalplex MK e 0,5\% de tensoativo) por 20 minutos, após este tempo, adicinou-se mais $4 \%$ de kalplex MK permanecendo nesta solução por mais 20 minutos. As peles foram lavadas com tensoativos e colocadas em solução de píquel.

No píquel as peles foram submetidas a solução de água e sal a 8 baumé, por 10 minutos. Depois adicionou-se na 
solução $2 \%$ de ácido fórmico diluído em água. Após a estabilização do $\mathrm{pH}(\mathrm{pH}=4,0)$, que ocorreu em 60 minutos com o fulão em rotação, foi adicionado o agente curtente. Iniciando assim a etapa de curtimento, cuja banho (solução) utilizado foi o mesmo do píquel, com adição apenas de 10\% de tanino vegetal (Weibull@). Agora chamados de couros, estes permaneceram nessa solução por 24h para depois serem basificados (1\% bicarbonato de sódio e $0,5 \%$ de tensoativo, sendo adicionado solução em três partes a cada 15 minutos). Após 24 horas nesse banho, os couros foram retirados do fulão e colocados em repouso num recipiente coberto com plástico, para não secarem por um período de $48 \mathrm{~h}$.

Depois desse período os couros foram neutralizados (1,5\% bicarbonato de sódio e $0,5 \%$ de tensoativo), recurtidos e tingidos (4\% de tanino vegetal, $1 \%$ tensoativo e $2 \%$ óleo Superderma F1), engraxados com emulsão de óleos (4\% Superderma GW® e 4\% Superderma $A F\left(\right.$ ) a $50^{\circ} \mathrm{C}$, sendo que cada etapa foi realizada em 60 minutos com fulão em rotação. Na solução do engraxe foi adicionado $0,5 \%$ de ácido fórmico diluído, para a fixação dos óleos, em 10 minutos de rotação do fulão. Após, foi realizada a remontagem de cor, utilizando mais $1,5 \%$ do mesmo corante utilizado na etapa de recurtimento/ tingimento e permanecendo mais 20 minutos em rotação. Finalizando o processo foi adicionado mais $1 \%$ de ácido fórmico diluído para fixação. Sendo assim, foram obtidos dois tratamentos; peles de salmão (trat1) e peles de tilápia (trat2), cujo processamento foi realizado dentro do mesmo fulão, para não ocorrer diferença no processo de curtimento. Após os couros secos foram retirados os corpos de provas na região central do couro, no sentido longitudinal ao comprimento do peixe.

\subsection{Testes de Resistência}

Foram retirados dez corpos-de-prova de couros curtidos de cada espécie de peixe, com auxílio de balancim. Os corpos de provas foram retirados no sentido longitudinal ao comprimento do corpo dos peixes para a determinação da resistência à tração, ao alongamento (ABNT - NBR ISO 3376, 2014) e ao rasgamento progressivo (ABNT - NBR 3377-2, 2014). Após os couros foram encaminhados ao laboratório climatizado $\left(23^{\circ} \mathrm{C}\right.$ e $50 \%$ de umidade relativa do ar), por 24 horas, conforme ABNT (NBR ISO 10455, 2021) e verificadas as espessuras de cada amostra em dois pontos determinados pelas normas (ABNT - NBR ISO 2589, 2016) para a posterior realização dos testes de resistência. Os corpos de provas foram submetidos ao dinamômetro EMIC para a determinação da tração e alongamento e rasgamento progressivo. Para realização dos testes o dinamômetro EMIC foi calibrado para a velocidade de afastamento entre cargas de $100 \pm 20 \mathrm{~mm} / \mathrm{min}$. Foi utilizada uma célula de carga de $200 \mathrm{kgf}$. O equipamento foi calibrado pela EmicDcame, laboratório de calibração credenciado pela CGCRE/inmetro sob nº 197.

\subsection{Análises Estatísticas}

Foi utilizado um delineamento inteiramente casualisado com dois tratamentos (sendo Trat 1-Tilápia e Trat 2 Salmão), com 10 repetições, sendo o couro a unidade experimental.

Os corpos de provas foram retirados no sentido longitudinal do comprimento do corpo do peixe para avaliação dos testes de resistência. Os resultados foram submetidos à análise de variância ANOVA, usando o PROC GLM do SAS (2010) e as médias comparadas pelo teste de $\mathrm{F}$ a $5 \%$ de probabilidade.

\section{Resultados e Discussão}

Uma observação notável e importante observada nos couros de tilápia e de salmão, é quanto às características da superfície do mesmo. Vale a pena relatar, pois são características específicas observadas para cada uma das duas espécies avaliadas neste trabalho. Na superfície existem lamélulas onde as escamas ficam incrustadas, consideradas de lamélulas de proteção e inserção das escamas, que forma um mosaíco inimitável nas peles de peixes de escamas (Almeida, 1998; Souza, 2004). De acordo com Adeodato (1995) com a remoção das escamas do peixe, após o curtimento, resulta em um couro de 
aspecto típico, caracterizando a espécie e difícil de ser imitado, garantindo exclusiva padronagem de alto impacto visual, sendo considerada de desenho de flor. Segundo Souza (2003) o desenho de flor também é uma característica própria de cada espécie após o curtimento, constituindo uma definição de cada tipo de pele, em função da espécie de peixe. Por melhor que seja as tecnologias atualmente, ainda não existe nenhuma que possa imprimir fielmente esse desenho, referente as lamélulas em um couro de bovino. Em couros que apresentam baixa qualidade, decorrente de marcas de bernes ou carrapatos, na superfície do couro, após o curtimento os curtumes utilizam tecnologia com aplicação de massas especiais e chapas com as características desejada para ser impressa no couro, uma forma de agregar valor a esse couro. Por exemplo o desenho de flor de um couro de jacaré ou de avestruz. Porém, para o peixe, por melhor que seja a tecnologia, dificulta, pelo fato das lamélulas apresentarem um comprimento variável com a espécie de peixe e elas ficarem soltas, exatamente no local onde estaria inserida a escama, dificultando a imitação dessa característica em um couro de bovino, por exemplo.

Na Figura 1 pode ser observado o desenho de flor das duas espécies de couros avaliadas neste trabalho. O couro de tilápia apresenta as lamélulas maiores e mais profundas em relação do couro de salmão. Mas, uma característica importante para ser observada nesses couros é quanto a presença da linha lateral. No couro de tilápia não é possível notar a presença da linha lateral, enquanto no couro de salmão é nítido o local dessa linha lateral, pois as escamas são diferenciadas, assim como, as lamélulas referentes a esse local (seta). A importância desse fato, num processo de curtimento de peles de peixes, é decorrente da maior dificuldade de remoção dessas escamas, necessitando muitas vezes de um maior tempo na etapa de caleiro.

Figura 1 - Couro de salmão (a) e tilápia do Nilo (b), mostrando as lamélulas de proteção e inserção das lamélulas. Linha lateral no couro do salmão (seta), com algumas escamas inseridas e a lamélula diferenciada do restante desse couro.

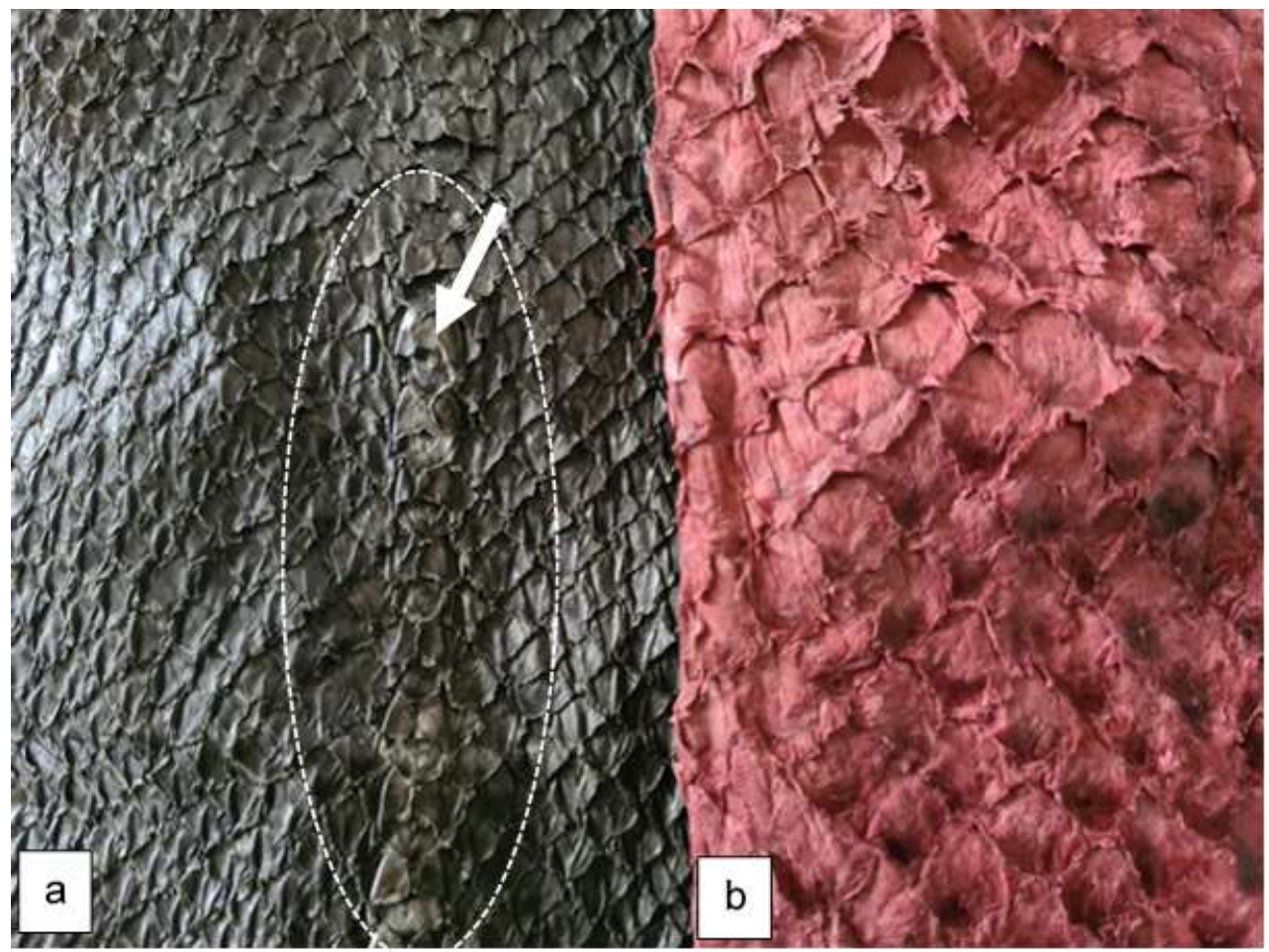

Fonte: Autores.

Existem couros com lamélulas muito maiores, como exemplo de pirarucu. Souza et al. (2020) relataram que independentemente da qualidade de resistência do couro de pirarucu, a sua beleza, decorrente das suas lamélulas de proteção e inserção das escamas é o que mais valoriza esse tipo de couro. $\mathrm{O}$ fato das lamélulas serem maiores e mais profundas, se tornam 
mais perceptíveis e interessantes para uso em confecções de bolsas e calçados.

Neste trabalho foi comparando as características de resistência dos couros de duas espécies de peixes, sendo uma marinha (Salmão) e outra de água doce (Tilápia). Existem diferenças acentuadas entre as peles das várias espécies de peixes, quanto a arquitetura histológica (disposição, orientação das fibras colágenas) da própria pele, a composição das fibras colágenas, principalmente em relação a hidroxiprolina (quando são comparadas as peles de peixes marinhos e de água doce), assim como, a composição química das peles (quantidade de gorduras presente), a idade e peso interferindo na espessura da pele, consequentemente na quantidade de fibras colágenas sobrepostas, no sentido da pele (transversal ou longitudinal ao comprimento do corpo do peixe), conservação e o no processo ou técnica de curtimento aplicado (Souza et al., 2003; Souza, 2004; Franco et al., 2013 e Yoshida et al., 2016). De acordo com esses diversos fatores listados, as peles necessitam de técnicas diferenciadas de curtimento, seja em tempo, quantidade e tipos de produtos, acréscimo de um ou outro produto químico (Hilbig, et al., 2013; Franco et al., 2015), até mesmo acréscimo de etapas. Também Franco et al. (2013) afirmam que são muitos os fatores que influenciam na qualidade de resistência de um couro e apenas uma etapa ou dependendo da etapa, principalmente o caleiro, purga e píquel, devido à maior agressão proporcionada a pele que está sendo processada, é o suficiente para reduzir e muito a resistência do couro de peixe.

Para evitar qualquer efeito do processo de curtimento, as peles neste experimento foram curtidas juntas, todas recebendo os meus produtos químicos, ao mesmo tempo, assim como o tempo de cada etapa, de forma que o procedimento fossem os mesmos para peles de salmão e de tilápia. Observando os resultados nas Tabelas 1 e 2, nota-se que houve diferença entre alguns parâmetros analisados, enquanto para outros não apresentaram diferenças significativas.

Na Tabela 1, pode-se verificar que os couros das diferentes espécies não apresentaram diferenças significativas para as variáveis de espessura, deformação e tração, cujos valores médios foram 0,84 mm, 63,44 mm e 17,31 N/mm2, respectivamente. Contudo, o alongamento para os couros de tilápia $(114,75 \%)$ foi significativamente superior ao de salmão $(96,00 \%)$. Todavia, a força utilizada foi inversamente proporcional, sendo menor para os couros de tilápia $(127,00 \mathrm{~N})$ e maior para os couros de salmão $(161,75 \mathrm{~N})$. Isto mostra que as peles de salmão embora possua uma menor elasticidade, ainda assim necessita de uma maior força para promover o rompimento do couro. Podendo, isto estar associado a presença de fibras do tipo reticulina que amarram as fibras colágenas, dificultando mais o rompimento dessas fibras. Portanto, esse couro necessitou exercer mais força para proporcionar essa elasticidade, mesmo sendo significativamente inferior aos resultados do couro de tilápia. Já Franco et al. (2013) analisando o força aplicada nos couros de salmão, curtidas com sais de cromo, relataram que foi $58,33 \mathrm{~N}$, valor este bem inferior ao obtido neste trabalho com tanino vegetal $(161,75 \mathrm{~N})$, podendo estar associado ao curtimento com cromo, pois para essa técnica necessita-se de um valor de $\mathrm{pH}$ muito inferior para a etapa de píquel. Com isso, pode ter destruído parcialmente algumas fibras colágenas que dá estruturação a derme, como exemplo as fibras de reticulina ou fibras colágenas finas, nos couros de salmão curtidos com cromo. Esse fato evidenciado, associado a questão da resistência a tração $(10,90 \mathrm{~N} / \mathrm{mm} 2)$, relatado pelos autores ser muito inferior ao obtido neste experimento para o couro de salmão $(15,81 \mathrm{Nmm} 2)$ justifica dizer que a técnica de curtimento com cromo proporcionou um couro menos resistente que os couros avaliados neste trabalho.

Os couros de salmão curtidos com sais de cromo também apresentaram menor espessura $(0,67 \mathrm{~mm})$, podendo ter sido devido à perda de material colágeno da pele, em função do baixo valor de pH utilizado na etapa de píquel, que normalmente é de 3,0 (Franco et al., 2013). Neste experimento a espessura do couro de salmão $(0,82 \mathrm{~mm})$ foi superior ao relatado pelos autores supracitados, onde o pH do píquel foi de 4,0, valor superior ao usado por Franco et al. (2013). 
Tabela 1 - Teste de resistência tração e alongamento para as espécies tilápia e salmão curtidos com sais de cromo e e recurtidos com tanino vegetal

\begin{tabular}{lccccc}
\hline \multirow{2}{*}{ Couros } & \multicolumn{5}{c}{ Tração e Alongamento } \\
\cline { 2 - 6 } & Espessura & Força & Deformação & Alongamento & Tração \\
& $(\mathrm{mm})$ & $(\mathrm{N})$ & $(\mathrm{mm})$ & $(\%)$ & $\left(\mathrm{N} / \mathrm{mm}^{2}\right)$ \\
\hline Tilápia & $0,86 \pm 0,03^{*}$ & $127,00 \pm 17,37$ & $69,12 \pm 5,69$ & $114,75 \pm 9,38$ & $18,81 \pm 1,50$ \\
Salmão & $0,82 \pm 0,02$ & $161,75 \pm 18,01$ & $57,75 \pm 5,52$ & $96,00 \pm 9,42$ & $15,81 \pm 2,03$ \\
\hline Valor de p. & 0,5986 & 0,0467 & 0,0643 & 0,0158 & 0,1261 \\
\hline C.V. $(\%)^{* *}$ & 15,10 & 24,21 & 12,82 & 12,97 & 21,26 \\
\hline
\end{tabular}

*Médias \pm desvio padrão. Teste de F $(\mathrm{p}<0,05) * *$ C.V.= Coeficiente de Variação. Fonte: Autores.

Os resultados obtidos neste experimento não corroboram com os apresentados por Yoshida et al. (2016), quando avaliaram a qualidade de resistência de couros de diferentes espécies curtidas com sais de cromo. Segundo esses autores o alongamento não houve diferença significativa entre os couros de Salmão $(111,00 \%)$ e tilápia $(108,43 \%)$, enquanto neste experimento foi perceptível essa diferença (Tabela 1). Mas, Yoshida et al. (2016), conseguiram obter couros de salmão com maior elasticidade e de tilápia com menor, em relação aos deste experimento. Tudo indica que a formulação utilizada pelos autores proporcionou essa diferença na elasticidade dos couros. Os autores curtiram os couros com sais de cromo, enquanto neste trabalho foi com tanino vegetal.

A quantidade de hidroxiprolina no colágeno das peles de peixes difere entre as espécies, interferindo na temperatura de retração ou encolhimento da pele, logo após o curtimento, ocorrendo a ruptura dos enlaces de hidrogênio da cadeia de colágeno de forma irreversível. Com essa ruptura, dá-se a desnaturação proteica e, particularmente no colágeno, verifica-se a gelatinização, que morfologicamente se manifesta por uma forte contração das fibras no sentido longitudinal, o que torna as fibras transparentes e elásticas (Pasos, 2002). Consequentemente, isto pode afetar a estabilidade durante o processo de curtimento, sendo mais sensível o processo de curtimento das peles de salmão, comparado aos de tilápia. Portanto, a pele de salmão requer muito mais atenção para o processo de curtimento, em função de possuírem menor quantidade do aminoácido hidroxiprolina na cadeia de colágeno, comparado as peles de peixes de águas tropicais. De acordo com Franco et al. (2013) existem etapas no processo de curtimento em que ocorre reações exotérmicas, como exemplo na etapa de caleiro (água, sulfeto de sódio e cal) e no píquel (água, sal e ácidos), tornando-a mais sensível a desnaturação. Segundo estes autores, além dessas duas etapas, uma outra que requer cuidados é a purga, pois, nessa etapa é utilizada uma enzima proteolítica, que atua diretamente no tecido dérmico. Caso a concentração da enzima seja utilizada em excesso, os autores mencionam que ocorrerá à digestão da pele, proporcionando a desnaturação das fibras colágenas e perda da estrutura dérmica ou apenas uma agressão à estrutura em função do tempo de exposição das enzimas à pele, nessa etapa de purga.

Todavia, como a técnica aplicada ficou em função da pele de salmão, por ser mais sensível, provavelmente as peles de tilápia não receberam a ação do tempo e produtos químicos em quantidades suficientes para obtenção do melhor resultado. A análise de rasgamento progressivo apresentou um resultado significativamente inferior para os couros de tilápia comparado aos de salmão. Em geral os couros de tilápias tem apresentado um valor para o rasgo variando de 40,18N/mm a 79,17N/mm (Franco et al. 2013; Yoshida et al., 2016), em função da técnica aplicada de curtimento (quanto ao percentual e tipo de agente curtente utilizado no processo, quantidade de óleo no engraxe e tanino no recurtimento) (Souza et al., 2014; Franco et al., 2015). Já as de salmão o valor varia de 19,68N/mm a 105,69N/mm, considerando os mesmos fatores mencionados para tilápia 
(Franco et al. 2013; Yoshida et al., 2016). Nota-se, portanto, que para as peles de salmão a variação tem sido muito maior, refletindo nas dificuldades de processamento desta pele, comparado aos de tilápia, afetando consequentemente nos resultados finais do produto.

De acordo com a Basf (2004) os valores para couros curtidos de bovino à base de cromo a serem aplicados na indústria de vestuários devem apresentar o valor mínimo de resistência para o rasgo de 35N/mm. Por conseguinte, ambos os tratamentos estão com os parâmetros de acordo com os descritos por Basf (2004). Evidenciando, dessa forma que os couros de salmão apresentaram valores superiores aos de tilápia para o rasgamento progressivo (Tabela 2).

Tabela 2 - Rasgamento progressivo de couros de tilápia do Nilo submetidos ao curtimento com sais de cromo e recurtidos com tanino vegetal.

\begin{tabular}{lccc}
\hline \multirow{2}{*}{ Couros } & \multicolumn{3}{c}{ Rasgamento Progressivo } \\
\cline { 2 - 4 } & Espessura $(\mathrm{mm})$ & Força (N) & Rasgo (N/mm) \\
\hline Tilápia & $0,89 \pm 0,04^{*}$ & $36,75 \pm 8,43$ & $40,56 \pm 11,52$ \\
Salmão & $0,81 \pm 0,03$ & $53,62 \pm 8,37$ & $53,60 \pm 12,69$ \\
\hline Valor de p. & 0,3242 & 0,0151 & 0,0436 \\
\hline C.V $(\%)^{* *}$ & 16,46 & 49,05 & 39,88 \\
\hline
\end{tabular}

*Médias \pm desvio padrão. Teste de $\mathrm{F}(\mathrm{p}<0,05)$ **C.V.= Coeficiente de Variação. Fonte: Autores.

A força aplicada no teste de rasgamento progressivo para o couro de salmão $(53,62 \mathrm{~N})$ foi significativamente superior ao de tilápia $(36,75 \mathrm{~N})$, resultando em maior resistência ao rasgo $(53,60 \mathrm{~N} / \mathrm{mm})$ para os couros de salmão comparado aos de tilápia $(40,56 \mathrm{~N} / \mathrm{mm})$. As espessuras desses couros foram semelhantes, mostrando que não interferiu nesses resultados obtidos. Franco et al. (2013) obtiveram para couros de salmão uma média de 19,68N/mm aplicando uma força de $62,11 \mathrm{~N}$. Estes menores valores podem também estarem relacionados ao tipo de curtimento utilizado (sais de cromo), pois os valores foram muito inferiores aos obtidos neste trabalho com tanino vegetal (Tabela 2).

Talvez os resultados obtidos neste trabalho não tenham sido melhores para os couros de tilápia, pelo fato destes necessitarem mais tempo ou maior quantidade de produtos comparado aos couros de salmão, mostrando que as peles devem ser processadas separadas em função da espécie de peixe, pelo fato destas apresentaram diferenças em sua constituição e estrutura histológica.

\section{Conclusão}

O curtimento de peles de peixes é um processo que possui viabilidade socioeconômica para o aproveitamento destes resíduos de filetagem. O método de curtimento ecológico com tanino vegetal, torna-os ambientalmente corretos por não empregar metais pesados como sais de cromo no curtimento, diminuindo o impacto no meio ambiente e ainda assim conferindo qualidade ao produto. Consequentemente ocorre aumento de aceitação do produto pelo mercado da confecção em geral. Desta forma, o uso do tanino vegetal é uma alternativa tecnológica viável para o processo de curtimento. Os couros de salmão apresentaram qualidade de resistência semelhante ou superiores aos couros de tilápia, dependendo do parâmetro avaliado em função da técnica aplicada. Recomenda-se que o curtimento de peles de peixes de diferentes espécies, sejam realizados separadamente, pois cada espécie tem suas particularidades, necessitando de diferentes tempos ou ações durante o 
processo de curtimento. Sugere-se que novas pesquisas sejam realizadas com novos percentuais de tanino vegetal para o curtimento de peles de salmão, bem como análises de resistência nos sentidos transversal, vertical e longitudinal ao couro, sugere-se também que seja avaliado a espessura dos couros correlacionados as análises de resistência, além da contagem de fibras colágenas e microscopia eletrônica de varredura.

\section{Referências}

Araujo, C. \& Reynol, F. (2017). Produção de tilápia cresce 223\% em de anos. Embrapa.

ABNT. (2021). NBR 10455: 2021 climatização de materiais usados na fabricação de calçados e correlatos. Associação Brasileira De Normas Técnicas ABNT. Rio de Janeiro: p. 2.

ABNT. (2014). NBR ISO 3376: 2014 couro - Ensaios físicos e mecânicos - determinação da força de rasgamento progressivo. Parte 1: rasgamento de extremidade simples. Associação Brasileira De Normas Técnicas - ABNT. p. 4.

ABNT. (2016). NBR 2589: 2016 determinação da espessura. Associação Brasileira De Normas Técnicas - ABNT. 2.

ABNT. (2014). NBR 3377-2: 2014 couro - Determinação da força de rasgamento progressivo. Associação Brasileira De Normas Técnicas - ABNT. 4.

Adeodato, S. (1995). Peles exóticas e ecológicas. Globo Ciência, 51, 56-60.

Almeida, R. R. A. (1998). Pele de peixe tem resistência e flexibilidade? Revista do Couro, 127, 49-53.

Basf (2004). Vademécum do curtidor. (4a ed.), Ludwigshafen.

Dragnes, B. T., Stormo, S. K., Larsem, R., Ernstsen, H. H., \& Elvevoll, E. O. (2009). Utilization of fish industry residuals: Screening the taurine concentration and angiotensin converting enzyme inhibition potential in cod and salmon. Journal of Food Composition and Analysis, 22. 714-717.

Fasolo, V. (2011). Couros "Metal-free" e "Bioleather". Revista do couro. 216, 30.

Franco, M. L. R. S., Viegas, E. M. M., Kronka, S. N., Gasparino, E., Pontara, L. P., \& Del Vesco, A. P. (2015). Qualidade de resistência do couro de tilápia do Nilo em função da técnica de curtimento. Acta Tecnológica, 10, 24-31.

Franco, M. L. R. S. (2011). Transformação da pele do peixe em couro. Tecnologia do pescado: ciência, tecnologia, inovação e legislação. São Paulo: Atheneu.

Franco, M. L. R. S., Uchimura, C. M., Prado, M., Yajima, E. M., Gasparino, E., \& Silva, S. C. C. (2013). Quality of the skin of salmon, Salmo solaris: resistance test. Arquivos de Ciências do Mar. 46, $90-95$.

Fuck, W. F., Gutterrres, M., Marcílio, N. R., \& Bordingnon, S. (2011). The influence of chromium supplied by tanning and finishing processes on the formation of $\mathrm{Cr}$ (IV) in leather. Brazilian Journal of Chemical Engineering, 28, 221-228.

Godoy, L. C., Gasparino, E., Franco, M. L. R. S., Franco, N. P., \& Dourado, D. M. (2010). Testes físico-mecânicos e físico-químicos do couro da tilápia vermelha. Arquivo Brasileiro de Medicina Veterinária e Zootecnia, 62, 475-480.

Hilbig, C. C., Fockink, D. H., Maluf, M. L. F., Boscolo, W. R., \& Feiden, A. (2013). Resistência do couro de tilápia e composição centesimal da pele nas operações de ribeira e curtimento. Scientia Agraria Paranaenses, 12, 258-266.

Hoinacki, E. (1989). Peles e couros - origens, defeitos, e industrialização. (2a ed.), Henrique d`Ávila Bertaso.

IBGE. (2019). Produção da pecuária municipal 2018. Instituto Brasileiro de Geografia e Estatística-IBGE, 84, 8.

Jardim, M. A. I. A. et al. Ensaios Preliminares no Uso de Tanino Vegetal no Curtimento da Pele de Avestruz (Struthio camelus domesticus ). Semana de biologia, 5., semana de produção científica do curso de ciências biológicas, 3., semana nacional de ciência e tecnologia, 1., Campo Grande, Resumos... Campo Grande: Uniderp, 2004. p. 34-36.

Kubitza, F. (2006). Aproveitamento dos subprodutos do processamento de pescados. Panorama da Aqüicultura, 16, 23-29.

Neu, D. H., Dallagnol, J. M., Klein, S., Maluf, M. L. F., Franco, M. L. R. S., \& Boscolo, W. R. (2015). Resistência do couro de tilápia do Nilo submetido a diferentes processos de curtimento. Archivos de zootecnia, 64, 291-298.

Pasos L. A. P. (2002). Piel de pescado. Disponível na internet: http://www.cueronet.com/exoticas/pescado.htm.

Pereira A. S., Shitsuka, D. M., Parreira, F. J., \& Shitsuka, R. (2018). Metodologia da pesquisa científica. UFSM.

Pott, A., \& Pott, V. J. (1994). Plantas do Pantanal. EMBRAPA-SPI.

Prado, M., Franco, M. L. R. S., Bielawski, K., Souza, E. D., Gasparino, E., Silva, S. C. C., \& Del Vesco, A. P. (2014) Características de resistência dos couros de pseudoplatystoma sp. submetidos a alterações do processo de curtimento. Revista Cientifica de Produção Animal. 1, 46-59.

Sammarco, A., \& Simoncini, A (1994). Curtimentos alternativos orgânicos, uma contribuição para a ecologia através de processo e produtos. Revista do Couro. 73. 
Research, Society and Development, v. 10, n. 8, e43910817242, 2021

(CC BY 4.0) | ISSN 2525-3409 | DOI: http://dx.doi.org/10.33448/rsd-v10i8.17242

SAS Institute Inc., (2010). The data analysis for this paper was generated using SAS/STAT software, Version 9.3 of the SAS System for Windows. Copyright@ 2010 SAS Institute Inc. SAS and all other SAS Institute Inc. product or service names are registered trademarks or trademarks of SAS Institute Inc., Cary, NC, USA.

Simões, M. R., Ribeiro, C. D. F. A., Ribeiro, S. D. C. A., Park, K. J., \& Murr, F. E. X. (2007). Composição físico-química, microbiológica e rendimento do filé de tilápia tailandesa (Oreochromis niloticus). Food Science and Technology, 27, 608-613.

Souza, M. L. R. (2004). Tecnologia para processamento das peles de peixe. Maringá: Eduem.

Souza, M. L. R., Corrêa, S. S., Coradini, M. L., \& Oliveira, G. G. (2020). Processamento do pirarucu, um peixe cada vez mais procurado pelos piscicultores. Panorama da aquicultura, 30, 51-63.

Souza, M. L. R., Cucatti, T., Andrade, M. B., Godoy, L. C., Tozzi, M. A. C., Cavallieri, R. F., \& Silva, L. O. (2004). Diferentes técnicas de recurtimento em peles de tilápia-do-Nilo (Oreochromis niloticus): qualidade de resistência. Ensaios Cienc, 8, 195.

Souza, M. L. R., Dourado, D. M., Machado, S. D., Buccini, D. F., Jardim, M. I. A., Matias, R., Correia, C., \& Ferreira, I. C. (2003). Análise da Pele de Três Espécies de Peixes: Histologia, Morfometria e Testes de Resistência. Revista Brasileira de Zootecnia, 32, 1551-1559.

Yoshida, G. M., Kunita, N. M., Souza, M. L. R., \& Gasparino, E. (2016). Análises mecânicas e físico-químicas de couros de tilápia, cachara e salmão. Archivos de Zootecnia, 251, 349-355. 